\title{
DEUS E DIABO NOS DETALHES: A ÉTICA EM BUBER E ADORNO
}

\author{
KÁTIA MENDONÇA
}

Usualmente nossa interpretação da violência converge para uma perspectiva limitada a atos contra a integridade física do homem. A adoção deste sentido restrito de violência nos impede de estabelecer uma reflexão sobre a sua vinculação com a ética presente nas esferas do interindividual, do cultural, do social e do político. Esse nexo entre ética e análise da violência só pode ser estabelecido se começarmos por perceber a violência como um processo com diversas facetas: simbólicas, psicológicas, físicas, etc.

Essa perspectiva ampliada de violência exige uma visão integral do homem. Vendo-o como portador de dimensões diversas e interligadas, a partir de uma perspectiva personalista e fenomenológica, podemos compreender seus atos como portadores tanto da violência quanto da eticidade.

Mas a percepção da violência sob o signo da ética - não a ética formal e neutra, mas uma ética que possa servir de guia à ação, como a proposta por Martin Buber - exigirá uma fenomenologia dos sentidos. Isso se apresenta na medida em que se a entende como a privação imposta ao outro do ato de falar, ouvir e olhar, privação esta que se expressa desde os condicionantes psíquicos e materiais para tal, até o ato físico propriamente dito, dimensão última da violência, mas não única. Sob esse viés a violência será sempre uma interdição à palavra do Outro, como lembrava Simone Weill.

Embora de filiações filosóficas distintas, Martin Buber e Theodor Adorno apontam para a possibilidade de uma leitura fenomenológica da violência.

Para além de suas raízes freudo-marxistas, é por meio de uma perspectiva fenomenológica que se pode fazer uma leitura da questão da violência em Elementos do Anti-Semitismo (Adorno \& Horkheimer, 1991) no qual Adorno e Horkheimer irão abordar a questão da alteridade e denun- 
ciar o elemento patológico contido no anti-semitismo. O essencial aqui é ver que as relações sociais violentas engendradas pelo preconceito ultrapassam em muito a questão anti-semita e irão dizer respeito, ou melhor, se estenderão para as relações sociais na modernidade, pois nada mais é do que uma crítica da modernidade que encontramos na Escola de Frankfurt. Adorno irá definir essas relações por meio da noção de ofuscamento, caracterizado pelo olhar que extingue o sujeito, que não o vê como dotado de humanidade. Irreflexão, ofuscamento, são a oposição à reflexão e ao esclarecimento cuja crítica Adorno e Horkheimer empreendem. Há aqui uma verdadeira fenomenologia dos sentidos do homem moderno que tem sua vida danificada pela razão instrumental.

O que importa aqui é perceber que o conceito de ofuscamento em Adorno e Horkheimer é antes de tudo de caráter ético e está repleto de um conteúdo teológico com raízes no judaísmo das quais a exortação de Isaías é um exemplo:

Repartir o pão com o faminto, acolher em tua casa os pobres sem abrigo, vestir os desnudos e não desdenhar teu semelhante.

Então tua luz romperá como a aurora

E tua ferida logo se curará;

Tua justiça andará diante de ti (Is, 58, 7-8)

Se deres pão ao faminto

E saciares a fome torturante,

Tua luz se erguerá nas trevas

E tua sombra se tornará meio-dia (Isaías, 58:10)1

Anteriormente, em O Fetichismo da Música e a Regressão da Audição, Adorno respondendo a Benjamin - que aponta a regressão do olhar e da percepção trazida pela reprodução técnica da produção estética e pela conseqüente perda da aura - levanta a questão da regressão da audição vinculada à indústria cultural. Embora não explicitada, é inegável em Adorno que a regressão dos sentidos irá corresponder a uma regressão na eticidade do homem moderno, domado como sujeito, individualista antes que indivíduo. Deste modo a regressão física dos sentidos irá corres ponder à regressão ética da sociedade marcada pelo "cárcere de ferro" imposto pela razão instrumental, base da violência.

${ }^{1}$ Vide Lima, Adamor. 
Falando do anti-semitismo, Adorno e Horkheimer indicam que a justificação desse mal (que desborda, ressalto, a questão anti-semita) não se encontra em nenhum lugar:

por mais corretas que sejam, as explicações e os contra-argumentos racionais, de natureza econômica e política, não conseguem fazê-lo, porque a racionalidade ligada à dominação está ela própria na base do sofrimento. Na medida em que agridem cegamente e cegamente se defendem, perseguidores e vítimas pertencem ao mesmo circuito funesto. O comportamento anti-semita é desencadeado em situações em que os indivíduos obcecados e privados de sua subjetividade se vêem soltos enquanto sujeitos (...) Só a cegueira do antisemitismo, sua falta de objetivo, confere uma certa verdade à explicação de que ele seria uma válvula de escape. A cólera é descarregada sobre os desamparados que chamam a atenção. E como as vítimas são intercambiáveis, segundo a conjuntura: vagabundos, judeus, protestantes, católicos, cada uma delas pode tomar o lugar do assassino, na mesma volúpia cega do homicídio, tão logo se converta na norma e se sinta poderosa enquanto tal. (...) Aação tornase realmente um fim em si autônomo, ela encobre sua própria falta de finalidade. $\mathrm{O}$ anti-semitismo conclama sempre a ir até o fim do trabalho. Entre o anti-semitismo e a totalidade havia desde o início a mais íntima conexão. Acegueira alcança tudo, porque nada com preende. (Adorno \& Horkheimer, 1991: 160, grifos meus)

Ainda aqui é o olhar que expressa o caráter da relação de eticidade presente entre os homens. Adotando uma linguagem teológica, Adorno e Horkheimer revelarão que:

o olhar penetrante e o olhar que ignora, o olhar hipnótico e o olhar indiferente, são da mesma natureza: ambos extinguem o sujeito porque a esses olhares falta a reflexão, os irrefletidos deixam-se eletrizar por eles. (...) Assim o ensimesmado é uma caricatura do poder divino. Assim como a seu gesto soberano falta inteiramente o poder de criação na realidade, assim também lhe faltam, como ao demônio, os atributos do princípio que ele usurpa: o amor atento e a liberdade auto-sustentada. Ele é mau, levado pela compulsão e tão fraco quanto sua força. Assim como se diz que a onipotência divina atrai as criaturas para si, assim também a potência satânica e imaginária tudo atrai para dentro de sua impotência, eis aí o segredo de seu domínio. (Idem:178-179) 
Embora crítico do existencialismo buberiano, Adorno não consegue fugir em momentos de sua obra de uma espécie de fenomenologia dos pequenos detalhes. Se o Deus de Buber é o Deus dos pequenos detalhes, o Demônio de Adorno também é o Demônio dos pequenos detalhes. $\mathrm{E}$ aí podemos ver que, embora distante de Buber, mantém com este algo em comum que é uma concepção micrológica da vida nos pequenos detalhes, herdeira provável da doutrina judaica das centelhas divinas. Adorno, embora tivesse se desviado para o ateísmo, mantém ainda assim vinculações fortes com o Deus hebreu.

O judaísmo - desde a proibição de gravar imagens até a de pronunciar em vão o Nome de Deus - contribui para a submissão da metafísica a uma progressiva demitologização. Esse um caminho rumo à racionalização e esforço para libertar o homem do mito. O não falar seu santo nome em vão mantém a integridade do transcendente, rejeitando e prevenindo qualquer atalho que tente quebrar isso ${ }^{2}$. Em Adorno (assim como em Buber, como veremos adiante) o demônio está na intencionalidade do sujeito quando regida pela razão instrumental. Por isso é que a música apresenta um caráter teológico e contém a possibilidade da presença de Deus pois, sendo diferente da linguagem intencional, o que tem a dizer é simultaneamente revelado e escondido.

Sua idéia é o Nome divino ao qual tem dado forma. É a oração demitologizada, livre da eficácia mágica. É o esforço humano fracassando como sempre, para nomear o Nome, não para comunicar significados. A música aponta para a verdadeira linguagem no sentido que o conteúdo é aparente nela, mas o faz à custa da não ambigüidade do significado, o qual migrou para a linguagem intencional ${ }^{3}$.

A verdadeira linguagem é aqui a revelação do absoluto. Esse sonho de uma verdadeira e divina linguagem não intencional deriva diretamente de Walter Benjamin ${ }^{4}$, para o qual a verdade é a morte da intenção. Ressalte-se que Benjamin, embora crítico, foi leitor e interlocutor de Buber, mantendo correspondência com ele. Presente em Adorno e Benjamin está também o diálogo com Rosenzweig que influenciou decisivamente Martin Buber. Para Rosenzweig, Deus não pode ser tematizado, categorizado ou subsumido do Universal porque ele é o Universal. Se para

\footnotetext{
2 Vide a esse respeito Kaufmann, David.

${ }^{3}$ Adorno. T., Quase uma Fantasia. In Kaufmann.

${ }^{4}$ Idem.
} 
Benjamin a revelação ocorre em um Éden mítico, para Rosenzweig ocorre na relação mundana intersubjetiva. Para ele a transcendência não impede uma relação com Deus, possível na relação intersubjetiva não-instrumen tal. Para Rosenzweig, o nome de Deus pode ser falado, porque tudo que tem um nome pode ser falado, desde que esteja presente e Deus nunca está ausente. Rosenzweig não está preocupado com a proibição do nome de Deus. Antes, preocupado com a comunicação intersubjetiva, ele vê Deus como uma ocorrência diária, mundana, presente na relação entre os homens (isso seria decisivo para Martin Buber!). Para Rosenzweig, o que tem um nome próprio não pode ser uma coisa, logo não pode ser reduzido a uma relação instrumental a qual impede a reconciliação entre universal e particular $^{5}$.

Esta é, acredito, a base que permitirá a Adorno enveredar por uma visão micrológica na qual o particular, diferindo do universal, pode conter uma partícula de liberdade. Diante de um todo que "é o não-verdadeiro", como ele diz, Adorno nos propõe trabalhar nas frestas da razão instrumental totalitária, que a tudo açambarca, que a tudo penetra. Domado o sujeito na modernidade, a possibilidade da autonomia está no singular. Numa apologia aos fragmentos, às fissuras, relevantes para o Absoluto, Adorno nos apresenta o comportamento ético de sujeitos fraturados, domados, vidas prejudicadas, impossibilitadas de participarem da reconciliação, mergulhadas que estão na reificação das relações sociais que sujeita o mundo a uma falsa reconciliação. Se o todo é falso, Adorno irá substituí-lo pelo evanescente e fragmentário que poderia conter a verdade (a obra de arte). Mais tarde Adorno irá se abrir para as frestas presentes na educação, capazes de permitir a constituição de personalidades não-autoritárias e de impedir que Auschwitz se repita. Esse movimento parece conter a possibilidade de um deslocamento da esperança nas possibilidades de libertação contidas na esfera estética para as presentes na esfera ética, dimensão que foi tematizada em toda sua obra mas, quase sempre, caindo em uma perspectiva sem saída e niilista.

É sob esse prisma - ético - que a leitura adorniana da dualidade progresso-barbárie se apresenta, no mínimo, como subversiva. É certo que a história da subversão do conceito de barbárie se inicia com Bartolomeu de Las Casas que dirá:

julgamos bárbaros aqueles que não têm escrita ou língua culta. Mas a gente das Índias poderia nos considerar barbaríssimos, porque não compreendemos a sua língua.

5 Vide Kaufmann. 
A visão de Las Casas está, porém, ainda presa a uma espécie de relativismo étnico mais tarde compartilhado por Montaigne e por LéviStrauss. Adorno certamente nos apresenta a subversão ética, antes que somente étnica, do conceito de barbárie, permitindo-nos novas leituras, ou releituras, da dualidade civilizado-bárbaro:

entendo por barbárie algo muito simples, ou seja, que, estando na civilização do mais alto desenvolvimento tecnológico, as pessoas se encontrem atrasadas de um modo peculiarmente disforme em relação à própria civilização - e não apenas por não terem em sua arrasadora maioria experimentado a formação nos termos correspondentes ao conceito de civilização, mas também por se encontrarem tomadas por uma agressividade primitiva, um ódio primitivo ou, na terminologia culta, um impulso de destruição, que contribui para aumentar ainda mais o perigo de que toda esta civilização venha a explodir, aliás uma tendência imanente que a caracteriza. (Adorno, 1995:155)

É a partir disso que podemos conceber o bárbaro como aque le que submete o Outro à violência - qualquer que seja a sua expressão: física, psicológica ou simbólica.

A barbárie em Adorno irá revelar-se tanto em uma percepção micrológica quanto em uma visão macro dos processos políticos e sociais. Ao lado do pogrom e de Auschwitz, teremos também o mundo em que "as grandes injustiças estão nos pequenos detalhes"; a miséria, o inferno e o mal presentes no particular.

Juliette ou Esclarecimento e Moral nos revela esses detalhes infernais de uma microética da modernidade da qual o personagem de Sade, preso no círculo de relações interindividuais instrumentais é exemplar, expressando o quanto a emoção e os sentimentos, o amor e o prazer, todos foram submetidos ao império do cálculo, assim como a frieza e a apatia dele decorrentes. Os personagens do Marquês de Sade, como o Merteuil das Ligações Perigosas de De Laclos, mergulham em uma apatia racionalmente construída, porque necessária ao predomínio da razão, no mesmo sentido em que Kant prega que "a apatia (considerada como fortaleza) é um pressuposto indispensável da virtude”.

Nesta fenomenologia da frieza os detalhes serão fundamentais. O demônio de Adorno e Horkheimer estará na ocupação fria e metodicamente instrumental do espaço e do tempo. Em Juliette todos os orifícios são ocupados, todos os espaços são utilizados, todo o tempo é apropriado pelo prazer instrumental, desvinculado do amor: 
Não foi apenas o amor romântico entre os sexos que, enquanto metafísica, sucumbiu à ciência e à indústria, mas todo o amor em geral, pois nenhum prevalece diante da razão: nem o da mulher pelo homem, nem o do homem pela amada, nem o dos pais, nem o dos filhos. (Adorno \& Horkheimer, 1991: 109)

O processo de Esclarecimento e o cálculo que subordina o sentimento até a sua eliminação total ("serão precisos pretextos para cometer um crime?", pergunta um dos personagens de Sade retomado por Adorno) terão seu ponto de conclusão lógica, segundo Weber, atingido na ética protestante que subordina a emoção, tornando-se esta também instrumental. A caridade do protestantismo ascético, despida de emoções e pautada em uma relação impessoal com o Outro, perde a doçura cristã do Novo Testamento subordinada à rigidez do Antigo:

O amor ao próximo - desde que só podia ser praticado para a glória de Deus e não em benefício da carne - é expresso, em primeiro lugar, no cumprimento das tarefas diárias dadas pela lex naturae, assumindo então um caráter peculiarmente objetivo e impessoal - aquele de serviço em prol da organização racional de nosso ambiente social. (Weber, 1987: 75 )

Neste sentido, o processo de desencantamento do mundo irá obedecer aos imperativos da "frieza que a tudo penetra" segundo Adorno, ou daquilo que ele chamaria de "adoecimento de contato" expresso nas relações marcadas pelo formalismo burocrático, pelos papéis e pela frieza.

A reconciliação da civilização com a natureza, que o cristianismo queria obter prematuramente através da doutrina do deus crucificado, permaneceu tão estranha ao judaísmo quanto o rigorismo do esclarecimento. Moisés e Kant não pregaram o sentimento, sua lei fria não conhece nem amor nem a fogueira. (Adorno \& Horkheimer, 1991: 108)

Se há um Demônio, há certamente um Deus e este nas possibilidades de uma leitura teológica de Adorno, como para Buber, estaria também na relação com o Outro,

pois a delicadeza entre seres humanos nada mais é do que a consciência da possibilidade de relações isentas de interesse. (Adorno, 1991: 34) 
Aí a própria raiz da barbárie profetizada por Max Weber. A razão instrumental faz da barbárie aquele processo que elimina o outro ou não o percebe em sua humanidade. Processo que torna o homem indisponível para o Encontro ético.

É refletindo sobre os Encontros e os Desencontros éticos, na contramão, inclusive, de um judaísmo promotor da racionalidade instrumental, que encontramos Martin Buber, que para tal irá buscar nas raízes do hassidismo popular elementos capazes de promover uma proposta ética subversiva desse quadro.

Buber irá tipificar a estrutura dual das relações humanas e da existência que se conforma a partir delas: a relação $\mathrm{Eu}-\mathrm{Tu}$ e a relação EuIsso. Na relação Eu-Tu há a presentificação do Eu cuja construção se dá através da relação com o Outro - o Tu. O encontro entre o Eu e o Tu é um evento no qual há o olhar face a face. Há reciprocidade. Enquanto na relação Eu-Tu o Eu é uma pessoa, na relação Eu-Isso, o eu é um eu egótico. Mesmo sendo uma dimensão necessariamente constitutiva da relação do homem com o mundo, a relação Eu-Isso originalmente não é boa, nem má, porém diz respeito a uma razão instrumental que permite ao homem se relacionar de modo ordenado e coerente com o mundo, responsável pelas aquisições científicas e tecnológicas da humanidade. Mas, na medida em que o homem se deixe subjugar pela atitude Eu-Isso ela será fonte de relações reificadas, interdição para o encontro do Outro e assim para a conformação da humanidade mesma que se realiza através do Outro e deste modo "se o homem não pode viver sem o Isso, não se pode esquecer que aquele que vive só com o Isso não é homem". (Buber, s/d)

O homem aqui é portador de uma dimensão ética dele indissociável. Homem que se constitui não à maneira do dasein heideggeriano, mas no e pelo diálogo com o Outro. Não o ser autocentrado lançado no mundo, mas a pessoa que se constrói na relação com o Outro e através desta com Deus.

Destaque-se, ainda, que se para Buber a pessoa se constitui através da relação com o Outro, para Adorno o mesmo se dá no que se refere ao indivíduo. E, neste sentido, quanto mais individualismo houver na sociedade, menos indivíduo nós temos (o indivíduo foi domado, diria Horkheimer).

Para Buber é a relação inter-humana que irá conter tanto a centelha divina, a presença de Deus, quanto Lúcifer ou o Mal.

Como o Demônio de Adorno, o de Buber irá se manifestar na relação instrumental, assim como o seu Deus se apresentará na relação des - 
pida de interesses. Isso permite-nos dizer que para Buber, como para Adorno, a violência irá residir na ação intersubjetiva de caráter instrumental.

Sob essa perspectiva podemos dizer que, no sentido buberiano, a personalidade é relacional, se constitui não como realidade em si, mas como existência que se constrói na relação com o Outro. Areciprocidade é fundamental na relação Eu-Tu. Dela decorre a resposta ao apelo dialógico, ou mais propriamente, em sentido ético, a responsabilidade. É dessa espécie de relação que nasce a comunidade, relação dialógica grupal única capaz de fazer surgir a "verdadeira vida entre os homens".

Dois tipos de existência humana surgem daí: a existência monológica, que não sai para fora de si mesma, nem na mais terna comunhão, como lembra Buber, e a dialógica, que "recebe, mesmo no extremo abandono, uma sensação áspera e revigorante de reciprocidade".

Comparando a dialogia com o amor, Buber dirá que não se pode equipará-los pois não se conheceu alguém em tempo algum que amasse todos os homens que encontrou. Deste modo "a dialógica não pode ser equiparada ao amor. Mas o amor sem a dialógica, isto é, sem um verdadeiro sair-de-si-em-direção-ao-outro, sem alcançar-o-outro, sem permanecer-junto-ao-outro, o amor que permanece consigo mesmo, é este que se chama Lúcifer" (Buber, 1982: 55).

É clara em Buber a presença, como em Adorno, de uma microética. Em Buber esse Deus dos pequenos detalhes tem raízes indiscutíveis na apropriação que ele faz da doutrina cabalística da elevação das centelhas.

Nessa doutrina o homem pode entrar em comunhão com o divino presente na realidade, fazendo elevar as centelhas divinas. Mas, se para o hassidismo essa comunhão aniquila a realidade, na medida em que promove a emergência do transcendente e do abstrato que dissolve o real, na interpretação de Buber, ao contrário, as centelhas divinas irão se elevar em tudo que o homem fizer com concentração e com alegria quando entra na relação com o Aqui e o Agora, com o real: "aqui, onde nos encontramos, a vida divina e oculta deve resplandecer". Aqui a ação humana é o veículo do agir místico e, dotada de eticidade, irá fazer emergir Deus. Como diz Scholem, Buber realiza uma "apropriação existencial das centelhas divinas ocultas em todas as coisas". Dissolve assim a separação entre "viver em Deus" e "viver no mundo", o "mal primário de toda 'religião"”.

Buber identifica, assim, três formas de diálogo: o autêntico, marcado pela inflexão em direção ao outro, pelo estar presente na relação, perceben- 
do o outro em sua humanidade; o dialogo técnico, "movido pela necessidade de entendimento objetivo" e o "monólogo disfarçado de diálogo"6.

Mesmo no diálogo técnico, como diz Buber, há a possibilidade de se estabelecer a relação ética que "aparece talvez na tonalidade da voz de um condutor de trem, no olhar de uma velha vendedora de jornais, no sorriso do limpador de chaminés".

Romper esses limites para fazer surgir a dialogia verdadeira é a nossa tarefa. Romper os limites que se impõem à interpretação dos signos presentes no mundo, dos sinais que revelam a presença de Deus. E, neste processo em que os detalhes são possibilidades de revelação do divino, "nada pode se recusar a servir de recipiente à palavra". Ocorre, porém, que, prisioneiros da razão instrumental e dos papéis que com ela criamos para nós, não estamos disponíveis para o Encontro. $\mathrm{Na}$ indisponibilidade para o Encontro dialógico verdadeiro encontra-se certamente, creio eu, o germe da violência. Romper com a couraça do papel racionalmente outorgado a nós no interior de relações sociais reificadas é a tarefa maior vinculada à Liberdade e à Responsabilidade:

Cada um de nós está preso numa couraça cujo papel é repelir os signos (...) Cada um de nós está preso numa couraça que, graças à força do hábito, deixa logo de sentir. São apenas instantes que atravessam a couraça e que incitam a alma à receptividade. $\mathrm{E}$ quando tal instante agiu sobre nós e nos tornamos então atentos, perguntamo-nos: "Que é que aconteceu aí de peculiar? Não era algo semelhante ao que me acontece todos os dias?", então podemos nos responder: "Realmente, nada de peculiar aconteceu, é assim todos os dias, só que nós não estamos aí presentes todos os dias. (Buber, 1982: 43)

A dialogia é essencialmente relação não-instrumental:

Pois onde a ausência de reserva reinou entre os homens, embora sem palavras, aconteceu a palavra dialógica de uma forma sacramental. (Buber, 1982: 36)

Esta abertura para a vida exige que nos dispamos de papéis que nos impedem de viver cada evento e cada encontro da maneira mais autêntica possível ${ }^{7}$, pois o sentido da vida está em cada detalhe, nas pequenas

6 Vide Buber, 1982: 54.

7 Vide Bartholo Jr., 2001: 77. 
coisas: "não está em cima, nem em volta, nem entre as coisas, mas em cada coisa, na experiência de cada coisa".

Aliás, se para Adorno a falta de sentido da vida encontra-se nos pequenos detalhes, para Buber, o sentido da vida encontra-se também ele nos pequenos detalhes. Se o primeiro aponta para o beco sem saída das microviolências cotidianas, o segundo aponta para a redenção no Deus das pequenas coisas, receptáculos da palavra divina:

Entretanto, os sons pelos quais é constituída a palavra - repito isto a fim de afastar um mal-entendido ainda possível, que consiste em crer que esteja me referindo a algo extraordinário, de dimensões sobrenaturais - são os acontecimentos do cotidiano da pessoa. É neles, como são agora, 'grandes'ou 'pequenos', que nos é dirigida a palavra e aqueles que são tidos por grandes não fornecem signos maiores que os outros. (Buber, 1982: 49)

Se para Adorno é no cotidiano que se inscreve a falta de sentido da vida, o desespero, a violência do olhar que extingue o sujeito e do ouvido que não o ouve, para Buber é no cotidiano que existe a possibilidade de Resposta, sem a qual não existe a Responsabilidade Ética por meio da qual o homem fala com Deus:

O que esperamos nós quando desesperados e, mesmo assim, procuramos alguém? Esperamos certamente uma presença, por meio da qual nos é dito que ele, o sentido, ainda existe. Renunciei, desde então, àquele fenômeno 'religioso'que não passa de uma exceção, de um realce, de um destaque, de um êxtase; ou ele renunciou a mim. Eu nada mais possuo a não ser o cotidiano do qual nunca sou afastado. O mistério não se revela mais; desapareceu ou então instalou sua moradia aqui, onde tudo se passa da forma como se passa. Não conheço mais outra plenitude a não ser a plenitude da exigência e da responsabilidade de cada hora mortal. (Buber, 1982: 47)

Buber e Adorno compartilharam algo em comum em suas vidas que certamente teve efeitos sobre suas reflexões acerca da violência: vítimas desta última, vivenciaram a experiência crucial do anti-semitismo. Ambos se movimentaram no universo da opressão e do estigma sofrendo os horrores daquilo que Buber denominou de "o monstro da alteridade" e, por vias diversas, levantaram problemas semelhantes para a questão das relações éticas na sociedade moderna. Retomá-los faz-se necessário espe- 
cialmente em um momento do mundo moderno no qual a crise de pessoa e a crise de espiritualidade se revelam nos pequenos atos da esfera privada, assim como nos da esfera pública. Mundo no qual se aprofundam ainda mais a indiferença em relação ao Outro exposta na apologia ao mercado, na fetichização da globalização, na política que se expressa por meio do espetáculo, nas massas miseráveis jogadas nos braços da violência e na barbárie sutil, porém não menos cruel do que Auschwitz.

Isso implica conceber as relações sociais e políticas como a possibilidade de uma dialogia somente apreensível sob a perspectiva da pessoa - entendida como integração de corpo e alma, ou no sentido de Mounier, "como atividade vivida de autocriação, de comunicação e de adesão, que se apreende e conhece a si mesma em seu próprio ato, como movimento de personalização". Daí a ação coletiva não poder ser concebida unicamente por meio de instituições políticas ou de estruturas econômicas.

Refletir sobre a sociedade e a política, portanto, só terá sentido se o fizermos a partir do primado da pessoa sobre as instituições, do primado da eticidade sobre as estruturas impessoais. Só por meio disso e da busca de uma espiritualidade comum poderemos ultrapassar os limites que se impõem, ou, como ressalta Václav Havel:

Não se trata evidentemente de constranger o homem a adorar tal ou qual divindade arcaica, a se ajoelhar diante dela (...). Trata-se de outra coisa: as diferentes formas de nossa espiritualidade devem ter consciência de sua conexão mútua ou de seu parentesco, se lembrar dos conteúdos espirituais que nela estavam nas origens e que são provenientes desta experiência essencial e fundamental da humanidade. Eu creio que lá reside a única via de renovação da responsabilidade real do homem em relação a si mesmo e ao mundo. E, ao mesmo tempo, a única via em direção a esta compreensão aprofundada entre culturas que lhe permita cooperar de uma maneira verdadeiramente ecumênica na elaboração de uma nova ordem mundial. (Havel, 1997: 132-33)

A contribuição de Adorno e de Buber, sem dúvida, reside na possibilidade de estabelecermos nexos entre o usualmente separado: o público e o privado, o cotidiano e o excepcional, o interindividual e o social. Níveis que só podem ser unidos por meio de uma perspectiva fenomenológica, mas cuja apreensão é necessária em uma abordagem na qual a ética perca seu sentido de neutralidade formal e torne-se ela mesma um instrumento do agir para a transformação do mundo. 
Eles nos convidam a pensar a ética a partir do comportamento individual e a analisar a violência contida nos pequenos gestos e nos pequenos detalhes. Somente há que lembrar que, enquanto Adorno, por conta de sua luta (talvez seja essa a palavra mais adequada: luta!) para afastar-se de um teísmo, nos deixa sem saída e sem esperança, Buber, na sabedoria que o qualifica como o último grande profeta judeu do século $\mathrm{XX}$, percebe que o caminho para conter a violência, como para Havel acima, está numa ética pautada na aceitação do Transcendente pois "a palavra daquele que quer falar com os homens, sem falar com Deus, não se realiza; mas a palavra daquele que quer falar com Deus, sem falar com os homens, extravia-se" (Buber, 1982: 48).

KÁTIAMENDONÇA é professora e pesquisadora do Programa de Ciências Sociais da UFPA.

\section{REFERÊNCIAS BIBLIOGRÁFICAS}

Adorno, T. \& Horkheimer, M. (1991). Dialética do Esclarecimento. Trad. Guido de Almeida, Rio de Janeiro, Zahar. (1992). Minima Moralia. Tradução Luiz Eduardo Bicca. São Paulo, Ática. (1982). O Fetichismo da Música e a Regressão da Audição. In: Os pensadores. São Paulo. Ed. Abril.

BARTHOLO JR. Roberto (2001). Você e Eu, Martin Buber, presença palavra. Rio de janeiro: Garamond.

Buber, Martin. S/d. Eu e Tu. Trad. Newton Aquiles von Zuben. São Paulo: Moraes. (1982). Do diálogo e do dialógico. Trad. Newton Aquiles von Zuben. São Paulo: Perspectiva.

Havel, Václav (1997). Il est permi d'espérer. Paris: Calmann-Levy.

KAUfMANn, David. S/d. Adorno and the name of God. www.webdelsol.com/FLASHPOINT/adorno.htm

Lima, Adamor (2002). Ofuscamento e Razão. Mimeo. UFPA.

SCHOLEM, Gershom (1994). O Golem, Benjamin, Buber e outros Justos: Judaica I.Trad. Ruth Joanna Sólon. São Paulo: Perspectiva.

Weber, Max (1987). A ética protestante e o espírito do capitalismo. São Paulo: Pioneira. 